\title{
Enhanced textile dye decolorization by marine-derived basidiomycete Peniophora sp. CBMAI 1063 using integrated statistical design
}

\author{
Rafaella C. Bonugli-Santos ${ }^{1,5}$ - Gabriela A. L. Vieira ${ }^{2}$ - Catherine Collins ${ }^{3}$.

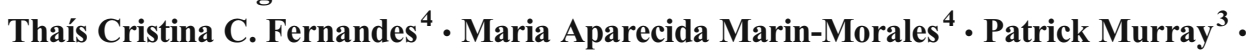 \\ Lara D. Sette ${ }^{1,2}$ (D)
}

Received: 8 October 2015 / Accepted: 4 January 2016 /Published online: 22 January 2016

(C) Springer-Verlag Berlin Heidelberg 2016

\begin{abstract}
In the present study, the biotechnological potential of the marine-derived fungus Peniophora sp. CBMAI 1063 was investigated in relation to Reactive Black 5 (RB5) dye decolorization and degradation using an integrated statistical design composed of Plackett-Burman design (P\&B), central composite design (CCD), and response surface methodology (RSM). RB5 dye was effectively decolorized $(94 \%)$ in saline conditions, without any detection of mutagenic compounds, and simultaneously, $57 \%$ of total organic carbon (TOC) was removed in 7 days. The activity of lignin peroxidase (LiP) was not detected during the process. The gene expression of laccase (Lac) and manganese peroxidase (MnP) enzymes produced during the
\end{abstract}

Responsible editor: Gerald Thouand

Electronic supplementary material The online version of this article (doi:10.1007/s11356-016-6053-2) contains supplementary material, which is available to authorized users.

\author{
Lara D. Sette \\ larasette@rc.unesp.br \\ Rafaella C. Bonugli-Santos \\ rafaella.santos@unila.edu.br \\ Gabriela A. L. Vieira \\ galv_bio@yahoo.com.br \\ Catherine Collins \\ catherine.collins@lit.ie \\ Thaís Cristina C. Fernandes \\ tccfbio@yahoo.com.br \\ Maria Aparecida Marin-Morales \\ mamm@rc.unesp.br \\ Patrick Murray \\ patrick.murray@lit.ie
}

process was evaluated, and results from this experiment coupled with LC-MS analyses revealed that in the early stage of dye decolorization, a higher MnP gene expression and significant enzymatic activity was detected in Peniophora sp. CBMAI 1063 with the formation of $\mathrm{p}$ Base and TAHNDS compounds. This paper reports innovative data related to the textile dye decolorization by the marine-derived basidiomycete Peniophora sp. CBMAI 1063, showing the metabolites formed and enzymatic action throughout the process in saline condition. The strategy used showed to be an efficient statistical approach that provides an attractive solution for the screening and simultaneous optimization of the degradation process.
1 Divisão de Recursos Microbianos, Centro Pluridisciplinar de Pesquisas Químicas, Biológicas e Agrícolas, Universidade Estadual de Campinas, Paulinia, SP, Brazil

2 Departamento de Bioquímica e Microbiologia - IB, Universidade Estadual Paulista Júlio de Mesquita Filho - UNESP, 24A, 1515 13506-900 Rio Claro, SP, Brazil

3 Shannon Applied Biotechnology Centre, Limerick Institute of Technology, Limerick, Ireland

4 Departamento de Biologia, Instituto de Biociências, Universidade Estadual Paulista Júlio de Mesquita Filho, Rio Claro, SP, Brazil

5 Present address: Instituto Latino Americano de Ciências da Vida e da Natureza, Universidade Federal da Integração Latino-Americana Unila, Paraná, PR, Brazil 
Keywords Textile dye degradation · Dye decolorization . Marine-derived fungi $\cdot$ Experimental design $\cdot$ Ligninolytic enzymes $\cdot$ Microbial biotechnology

\section{Introduction}

Textile dyeing wastewater has a large amount of complex components with a high concentration of organic and highcolor compounds. Some dyes used in textile industries are problematic for various aquatic microorganisms, plants and fish and can also cause human health disorders and severe damage to important human organs. Even today, color treatment and removal of these effluents can be considered a biotechnological challenge (Khan et al. 2013).

Reactive Black 5 (RB5) belongs to the group of reactive azo dyes and has been extensively used in textile industries all over the world, transported to rivers as part of industrial effluents. The exposure to this dye can cause human allergenic problems (respiratory tract), and some of the metabolites generated from its degradation can be carcinogenic (Usha et al. 2006). Additionally, the presence of RB5 dye in effluent can cause eutrophication of rivers and lakes due to the oxygen deficiency, resulting in algae growth and death of aquatic life, as well as, in a reduction of the photosynthesis process efficiency (Bardi and Marzona 2010, Hadibarata et al. 2013).

Dye decolorizing ability of ligninolytic fungi has been extensively studied in terrestrial basidiomycetes (Kaushik and Malik 2009); however, studies related to marine-derived fungi are still scarce. Enzymes produced by fungi from marine origin can offer different properties from their terrestrial counterparts (Trincone 2010). The adaptability of these microorganisms to oceanic conditions can be considered an attractive point in the field of fungal marine biotechnology, including the treatment of industrial colored effluents, which usually present extreme $\mathrm{pH}$ values and high amounts of salts (Bonugli-Santos et al., 2015). Sodium even in small concentrations is toxic to most of the living cells that inhabit terrestrial and freshwater environments (Raghukumar et al. 2008).

Nutrients and physical parameters have a significant effect on dye decolorization (Singh et al., 2013). Statistical tools are considered as an efficient approach to determine the best culture conditions in biotechnological processes and are also useful for environmental studies (Pearce et al. 2013, Zeng and Arnold 2014). Experimental designs were successfully applied for the optimization of the ammonium removal process in wastewater (Yingling and Zhengfang 2013), to enhance the chrysene degradation (Ghevariya et al. 2011), and for the optimization of biohydrogen production (Liu et al. 2011).

In this context, the purposes of the present study are to investigate the enhancement of the RB5 decolorization by the marine-derived basidiomycete Peniophora sp. CBMAI 1063 using integrated statistical design and also to assess the contribution of ligninolytic enzymes during RB5 dye decolorization, as well as to evaluate the metabolites generated during the degradation process.

\section{Materials and methods}

\section{Microorganism}

The marine-derived fungus Peniophora sp. CBMAI 1063 was isolated from the Brazilian sponge Amphimedon viridis collected in the town of São Sebastião, São Paulo State, Brazil (Menezes et al. 2010) and taxonomically identified as previously reported by Bonugli-Santos et al. (2010). The strain was deposited at the Brazilian Collection of Microorganisms from Environment and Industry-CBMAI.

\section{Fungal preparation and growth}

Peniophora sp. CBMAI 1063 was cultivated in $2 \%(w / v)$ malt extract agar (MA2) for 7 days at $28{ }^{\circ} \mathrm{C}$ (Table 1). For the experimental design, two to four fungal culture plugs ( $0.5 \mathrm{~cm}$ diameter) from the edge of the colony were transferred to $250-\mathrm{mL}$ Erlenmeyer flasks containing $50 \mathrm{~mL}$ of liquid medium according to Table S1 and S2 (Supplementary material) for Plackett-Burman design (P\&B 16 and 12) and to Table S3 (Supplementary material) and Table 2 for Central Composite Design (CCD). In the P\&B, the assays were incubated at different temperatures (supplementary material, Table S1) and in the $\mathrm{CCD}$ at $28^{\circ} \mathrm{C}$. After $72 \mathrm{~h}$, the Reactive Black 5 (RB5) dye was added to the assays at different concentrations as showed in Table S1 (P\&B 16). For all other experimental designs, $200 \mathrm{mg} / \mathrm{L}$ of RB5 was used. All assays were performed under saline condition according to the volume of artificial seawater (ASW) added to the medium (Bonugli-Santos et al. 2010). In P\&B 16 (Table S1), three different salinity conditions were used. Salinity corresponds to the ASW concentration (4\%) and was measured using a salinity meter. Three different volumes of ASW were added to P\&B 16 in order to achieve $1.2 \%$ salinity ( $15 \mathrm{~mL}$ of ASW and $35 \mathrm{~mL}$ of distilled water), $2.6 \%$ (32.5 mL of ASW and 17.5 of distilled water), and $4 \%$ (50 mL of ASW). For all other experimental designs and in the validation assay, the salinity was $1.2 \%$.

Assays were incubated for 7 days at $140 \mathrm{rpm}$ and $28^{\circ} \mathrm{C}$. Cultures were harvested by centrifugation at $12,074 \times \mathrm{g}$ for 30 min (Eppendorf Centrifuge 5804R), and the supernatant was used for the enzymes quantification, evaluation of the dye decolorization, and degradation and the AMES assay.

After experimental design, the optimized conditions were the following: three fungal culture plugs in $50 \mathrm{~mL}$ of liquid medium prepared with $3 \mathrm{~g} / \mathrm{L}$ of malt extract, $3 \mathrm{~g} / \mathrm{L}$ of wheat bran, $15 \mathrm{~mL}$ of ASW, and $\mathrm{pH}$ 6.25. The assays were carried out at $28^{\circ} \mathrm{C}$ and $140 \mathrm{rpm}$. After $72 \mathrm{~h}$ of incubation, $200 \mathrm{mg} / \mathrm{L}$ 
Table 1 Second central composite design (CCD) matrix, experimental data, and predicted values by the response surface analysis of RB5 decolorization by Peniophora sp. CBMAI 1063 incubated at $140 \mathrm{rpm}$ for 7 days

\begin{tabular}{llll}
\hline Run & \multicolumn{2}{l}{ Variables $^{\mathrm{a}, \mathrm{b}}$} & Decolorization (\%) \\
\cline { 2 - 3 } & Malt extract & Wheat bran & \\
\hline 1 & $0.065(-1)$ & $0.079(-1)$ & 57 \\
2 & $0.14(+1)$ & $0.079(-1)$ & 90 \\
3 & $0.065(-1)$ & $0.22(+1)$ & 88 \\
4 & $0.14(+1)$ & $0.22(+1)$ & 62 \\
5 & $0.05(-1.41)$ & $0.15(0)$ & 89 \\
6 & $0.15(+1.41)$ & $0.15(0)$ & 90 \\
7 & $0.1(0)$ & $0.05(-1.41)$ & 70 \\
8 & $0.1(0)$ & $0.25(+1.41)$ & 69 \\
9 & $0.1(0)$ & $0.15(0)$ & 89 \\
10 & $0.1(0)$ & $0.15(0)$ & 86 \\
11 & $0.1(0)$ & $0.15(0)$ & 86 \\
12 & $0.1(0)$ & $0.15(0)$ & 87 \\
\hline
\end{tabular}

${ }^{\mathrm{a}}$ In parenthesis, coded values

${ }^{\mathrm{b}}$ Values in $\mathrm{g} / 50 \mathrm{~mL}$

of RB5 was added to the medium. The validation assay was performed in triplicate, and the supernatant was obtained as described above.

\section{Experimental design and optimization of dye decolorization by Peniophora sp. CBMAI 1063}

The strategy used in the experimental design was composite by two P\&B (matrix 16 and matrix 12), two CCD, and the validation assay. The integrated statistical design was initialized by the selection of significant factors using $\mathrm{P} \& \mathrm{~B}$ model. The P\&B 16 was used to evaluate 12 independent factors, with initial values determined by preliminary experiments based on literature reviews (Table S1). Three assays on center point were added to the matrix in order to determine the standard error. The design matrix created by the statistical STATISTICA 7 from Statsoft Inc. (2325 East 14th Street, Tulsa, OK, 74104, USA) is also represented in Table S1. After standardized effect (estimate) by statistical analysis of results from $\mathrm{P} \& \mathrm{~B} 16$, new ranges of some independent factors (variables) were again evaluated, and other variables were eliminated or fixed in the P\&B 12 matrix (Table S2). The standardized effect was based on the following first-order polynomial model:

$\mathrm{y}=\beta_{0}+\sum \beta_{i} x_{i}$

where $y$ was the predicted response, $\beta_{0}$ was the model intercept, $\beta_{i}$ was the linear coefficient, and $x_{i}$ was the independent variable level.

Following the strategy based on the results of $P \& B$, the experiment was further expanded to a central composite design CCD (Table S3) with three variables: glucose, malt extract, and wheat bran. A $2^{3}$ randomized factorial central composite design (CCD) with six axial points $\alpha=\left(2^{3}\right)^{1 / 4}$ and four replicates at the center points leading to a total 18 experiments was employed to optimize the decolorization of RB5 dye Peniophora sp. CBMAI 1063. These experiments were performed to obtain a second-order model to predict the percentage of decolorization on functions of different variables. The quadratic model for predicting the optimal point was expressed as follows:

$y=\beta_{0}+\sum \beta i x i+\sum \beta i i x 2 i+\sum \beta i j x i x j$
Table 2 Metabolites identified according molecular weight by LC-MS analyses

\begin{tabular}{lll}
\hline Compounds & $\begin{array}{l}\text { Molecular weight } \\
(\mathrm{m} / \mathrm{z})\end{array}$ & 201 \\
p-Base & 281 & Structure and chemical formula \\
Triaminohydroxynaphthalene \\
disulfonic acid (TAHNDS)
\end{tabular}


where $y$ was the predicted response, $\beta_{0}$ was the model intercept, $x_{\mathrm{i}}$ and $x_{\mathrm{j}}$ were the independent variable levels, $\beta_{\mathrm{i}}, \beta_{\mathrm{ii}}$, and $\beta_{\mathrm{ij}}$ were the linear quadratic and interaction coefficients, respectively.

Since the results demonstrated that the rate of decolorization was similar to P\&B 12 and this test has not achieved optimal conditions, a new CCD was carried out. The second CCD (Supplementary material, Table S4) evaluated two variables (malt extract and wheat bran). This CCD was performed as the first $\mathrm{CCD}$, and a $2^{2}$ randomized factorial central composite design (CCD) with four axial points, $\alpha=\left(2^{2}\right)^{1 / 4}$, and four replicates at the center points leading to a total 12 experiments were employed to optimize the decolorization of RB5 dye by Peniophora sp. CBMAI 1063.

The quality of fit of the model equation was expressed by the coefficient of determination $\mathrm{R}^{2}$, and its statistical significance was determined by $\mathrm{F}$ test (analysis of varianceANOVA). The results were analyzed by the software STATISTICA 7. A significant level of $10 \%(P>0.1)$ was considered for the variables screened and $5 \%(P>0.05)$ for the central composite design.

To confirm the model equation adequacy, confirmatory experiments under the optimized condition were carried out. All the confirmatory experiments were conducted in triplicate, and the values predicted by the optimization model were set as controls.

\section{Evaluation of RB5 dye decolorization and degradation by UV/VIS and LC-MS analyses}

The evaluation of RB5 dye decolorization and degradation consisted of four trials using UV/VIS and LC-MS analyses allowing more complete coverage of the study: percentage of decolorization and kinetics, absorbance spectrum, quantitative degradation kinetics by LC-MS, and qualitative evaluation by LC-MS.

For the percentage and kinetics of the decolorization and absorbance spectrum analyses, the supernatants were diluted tenfold with distilled water prior to UV/VIS spectrophotometric analysis (Shimadzu UV-1240, Kyoto, Japan). The assays were performed as previously described (Bonugli-Santos et al. 2012). Color reduction was followed spectrophotometrically, and decolorizing activity was calculated from the decrease in the maximum absorption of RB5 peak. Absorption spectra were read in the wavelengths $300,400,500,600$, and $700 \mathrm{~nm}$ and dye decolorization at $598 \mathrm{~nm}$ (maximum absorption peak of this dye). To discard the mycelium participation in dye decolorization (dye adsorption by mycelium), the fungus was incubated for 7 days in the same conditions and without adding the RB5 dye. After this period, the assays were autoclaved, $200 \mathrm{mg} / \mathrm{L}$ of RB5 dye was added, and the assays were again incubated at $28{ }^{\circ} \mathrm{C}$ and $140 \mathrm{rpm}$ after 7 days, the experiments were centrifuged according to standard procedures, and supernatant absorbance was measured as described above.

For the analyses using the liquid chromatography system and mass spectrometric detection (LC-MS), $2 \mathrm{~mL}$ of the supernatants were dried using the system speed vacuum for $12 \mathrm{~h}$. After the samples were diluted in $1 \mathrm{~mL}$ of methanol and injected onto a HPLC (Agilent 1260 series) connected to a Q-TOF mass spectrometer (Agilent 6520), samples were resolved by Agilent Zorbax Eclipse C-18 $(2.1 \mathrm{~mm} \times 150 \mathrm{~mm} \times 3.5 \mu \mathrm{m})$ HPLC column using the following elution system: Mobile phase was solvent A $2 \mathrm{mM}$ ammonium acetate and solvent $\mathrm{B} 1 \%$ acetonitrile using a gradient $(0-5 \min 100 \%$ solvent A, 5-7.5 min $99 \%$ solvent A, 7.5 $12 \min 5 \% \mathrm{~A}, 12-15 \min 99 \% \mathrm{~A}$,), which was pumped through the system at $0.5 \mathrm{~mL}$ min-1. Eluent from the HPLC column was directed through a diode array detector (DAD) set to monitor at 254, 665, 270, 238, 597, 600, 310, and $350 \mathrm{~nm}$. After passing through the DAD, $100 \%$ of the eluent was directed into the electrospray ionization source of the QTOF mass spectrometer. The mass spectrometer was operated in negative ionization mode scanning from $50-1100 \mathrm{~m} / \mathrm{z}$. Drying gas flow rate, temperature, and nebulizer pressure were at $6 \mathrm{~L}$ min- $1,325^{\circ} \mathrm{C}$, and $30 \mathrm{psi}$, respectively. Fragmentor and skimmer voltages were kept at 175 and 65 V, respectively (Xingzu et al. 2008).

For quantitative analysis, concentrations of 0.5 to $10 \mathrm{mg} / \mathrm{L}$ of BR5 dye were applied as standard. The peak area corresponding to the dye was calculated and used to determine the calibration curve. The dye concentration in each sample (first to seventh days of incubation) was achieved by applying the mathematical expression obtained from the standard curve $\left(\mathrm{R}^{2}=99 \%\right)$ :

$y=15.757 x+3.6171$

In the evaluation of metabolites formed during the degradation, the chromatographs were obtained with five different wavelengths $(310,597,270,238$, and $254 \mathrm{~nm})$ monitored by the detector diode. ESI scan mode and UV-visible ranges from 190 to $700 \mathrm{~nm}$ of each peak were used to determine the molecular mass of possible metabolites.

The total carbon reduction (TOC) analysis was performed with a total organic carbon analyzer, TOC-L Shimadzu. TOC measurement is based on the combustion of the total carbon (TC) by catalytic oxidation at high temperature. The equipment was set to provide a variation coefficient lower than $2 \%$ for each sample (in triplicates). The \%TOC reduction was calculated using Eq. (4)

$\%$ TOC reduction $=\left(\mathrm{TOC}_{\text {initial }}-\mathrm{TOC}_{(t)}\right) / \mathrm{TOC}_{\text {initial }} * 100$

where $\mathrm{TOC}_{(\text {initial) }}$ and $\mathrm{TOC}_{(\mathrm{t})}$ represent the initial TOC value and the TOC value at time "t" (h), respectively. Abiotic 
controls (without microorganism) were included during the experimental investigation.

\section{Contribution of ligninolytic enzymes in the RB5 dye decolorization}

Enzyme assays

All enzyme activities were measured spectrophotometrically (Shimadzu UV-1240, Kyoto, Japan) in triplicate. MnP activity was determined using manganese sulfate as substrate (Giardina et al. 2000). The reaction mixture contained $0.5 \mathrm{mM}$ manganese sulfate and $0.1 \mathrm{mM} \mathrm{H}_{2} \mathrm{O}_{2}$ in $50 \mathrm{mM}$ sodium malonate buffer, $\mathrm{pH} 4.5$. Oxidation of $\mathrm{Mn}^{+}$to $\mathrm{Mn}^{+}$ was followed by absorbance increase at $270 \mathrm{~nm}$ (e270 $=11590 \mathrm{M}-1 \mathrm{~cm}-1)$ due to the formation of malonate$\mathrm{Mn}^{+}$complex. LiP activity was determined by the oxidation of veratryl alcohol as previously described (Tien and Kirk 1984). The mixture reaction was composed of $0.5 \mathrm{~mL}$ enzyme

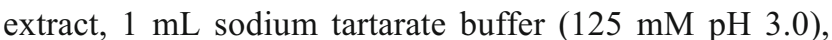
$0.5 \mathrm{~mL}$ veratryl alcohol $(10 \mathrm{mM})$, and $0.5 \mathrm{~mL}$ hydrogen peroxide $(2 \mathrm{mM})$. The reaction was initiated with hydrogen peroxide, and the appearance of veratraldehyde was measured at $310 \mathrm{~nm}$. Laccase activity was determined using 2.2'azinobis-(3-ethylbenzothiazoline (ABTS) as previously described by Buswell et al. (1995). The mixture was composed of $0.3 \mathrm{~mL}$ sodium acetate buffer $(0.1 \mathrm{M} \mathrm{pH} 5.0), 0.1 \mathrm{~mL}$ ABTS solution $(0.5 \mathrm{mM})$, and $0.6 \mathrm{~mL}$ enzyme solution. ABTS oxidation was measured by monitoring the increase in absorbance at $420 \mathrm{~nm}$.

One enzyme unit was defined as $1.0 \mu \mathrm{mol}$ of product formed per minute under the assay conditions, obtained from calculations performed from equation 5 , derived from the Beer-Lambert Law:

$\mathrm{U} \mathrm{L}^{-1}=\Delta \mathrm{A} \times \mathrm{V} \times 10^{6} / \varepsilon \times R \times t$

\begin{tabular}{ll}
\hline$\Delta \mathbf{A}$ & Difference between the final and initial absorbance \\
$\mathbf{V}$ & Reaction volume (total assay volume) \\
$\mathbf{1 0 ^ { 6 }}$ & Conversion of moles from $\varepsilon$ to $\mu \mathrm{mols}$ \\
$\boldsymbol{\varepsilon}$ & Extinction coefficient $\left(\mathrm{M}^{-1} \mathrm{~cm}^{-1}\right)$ \\
$\mathbf{R}$ & Amount of enzyme in the broth (L) \\
$\mathbf{T}$ & Reaction time (min)
\end{tabular}

\section{Enzymes expression}

The expression of genes, encoding laccase and MnP, was assessed by a semi-quantitative method. The total RNA was obtained from optimized assay (item 1) at times: zero and after second, fifth, sixth, and seventh days. The cells were filtered through cheesecloth to remove any liquid sample. The cells were then transferred to a mortar previously cleaned with $70 \%$ ethanol and $\mathrm{NaOH}$ in an ice bath. Then, a small aliquot of liquid nitrogen was added to the cells, and they were macerated with the aid of a pestle. This step was repeated until the formation of a powder (approximately three times). The macerated cells were transferred to polypropylene tubes and stored frozen at $-80{ }^{\circ} \mathrm{C}$. RNA extraction was performed using the RNeasy Plant Mini kit (Qiagen) according to manufacturer's instructions. To eliminate contaminating genomic DNA during the extraction, DNase was used for digestion. The extracted RNA was quantified spectrophotometrically $(260 \mathrm{~nm})$, and the RNA quality assessed electrophoretically in $0.8 \%$ agarose gel. For synthesis of the first cDNA strand, High Capacity RNA-to-cDNA kit (Applied Biosystems) was used.

Relative expression was performed by PCR using degenerate primer AMP 2'-(5'-ACG AGS TCM TCC GTC TKA CKT TCC-3') and AMP-6R (5'-GTT SAC GAA GCC CTG CCA GAW GC-3') as previously described (Morgenstern et al. 2008), CulAF (5'-ACM WCB GTY TGG CAY CAY GG-3') and Cu2R (5'-G CCA GAA GTA GTG RCT NGT NCC-3') as previously described (Kellner et al. 2007) and ITS1-5.8S-ITS2 for normalization (relative activity), as previously described (Sette et al. 2006). The relative levels of mRNA were determined by densitometric quantification using the Image J program of RT-PCR products obtained by electrophoresis on $1.2 \%$ agarose gel stained with ethidium bromide $(1 \mu \mathrm{L} .100 \mathrm{~mL})$. The results were expressed in arbitrary units.

\section{Results}

\section{Optimization of RB5 dye decolorization by Peniophora sp. CBMAI 1063 using experimental design}

The influence of 12 independent factors on RB5 dye degradation was investigated using $\mathrm{P} \& \mathrm{~B} 16$, and results are showed in Table S1. The decolorization ranges were from 10 to $70 \%$, and the optimal result was obtained in assay five, $70 \%$. The effects of the variables on the response and significant levels $(p<0.1)$ are shown in Fig. 1. Based on the statistical analysis, the factors having the greatest impact were peptone, yeast extract, dye concentration, and $\mathrm{CuSO}_{4}$, all with negative effect.

In order to improve the percentage of dye decolorization as well as to reduce the number of variables and to simplify the cultivation medium, the fungus was subjected to another P\&B (matrix 12), where eight variables were evaluated (Table S2), including significant variables in the first matrix (Fig. 1) whose concentrations were reduced, and the dye that was set at the center point $(200 \mathrm{mg} / \mathrm{L})$. Some variables that were not significant were set to: $\mathrm{pH} 6.25$, 
A

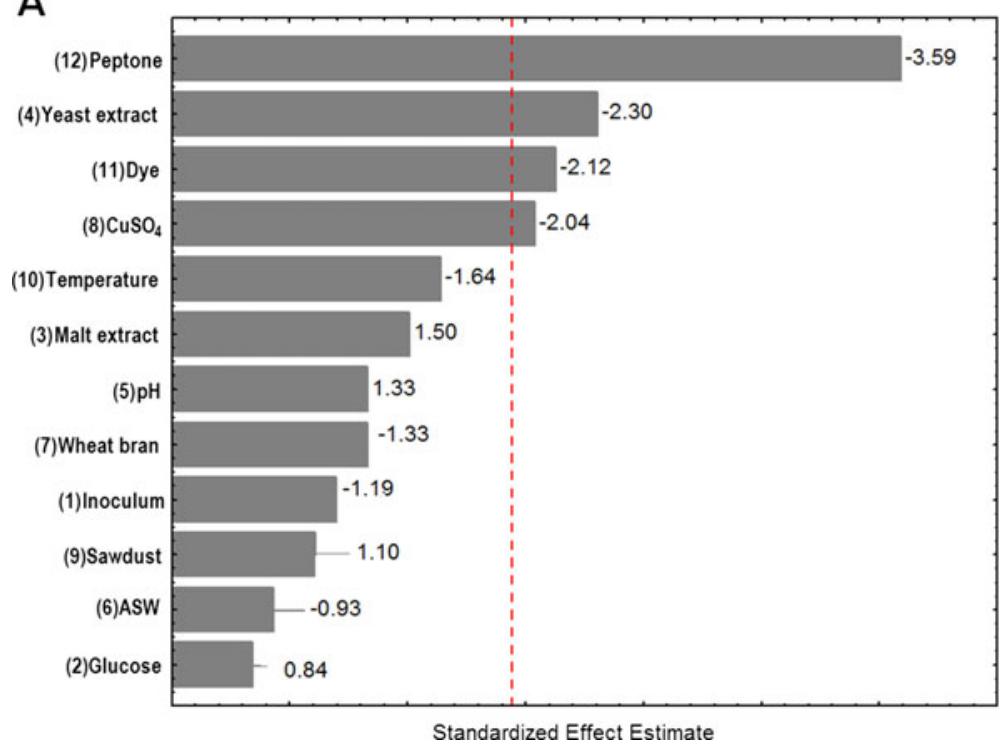

B

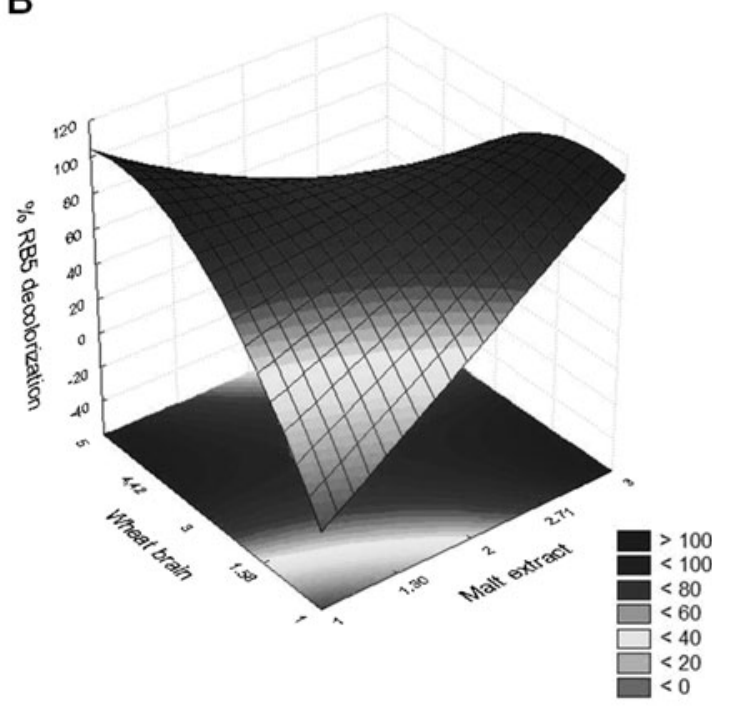

Fig. 1 Results from integrated statistical design. a Standardized Pareto chart showing the effects of the 12 independent factors on the RB5 dye decolorization. b Response surface curve and contour plots of the quadratic model for RB5 decolorization by Peniophora sp. CBMAI 1063

ASW $15 \mathrm{~mL}(1.2 \%)$, and inoculum (two plugs). Temperature, glucose, malt extract, wheat bran, and sawdust were again evaluated in other zones to confirm their relevance in the study.

In the second $\mathrm{P} \& \mathrm{~B}$, there was an improvement in the percentage of decolorization, where $91 \%$ was achieved in assay three (Supplementary material, Table S2). However, none of the variables were considered significant (date not shown). So, in the design of the next experiment, new values were defined taking into account the culture conditions of the assay that derived the highest rate of decolorization (assay three, Table S2). The variable temperature was set at $28{ }^{\circ} \mathrm{C}$, and the variables yeast extract, peptone, and $\mathrm{CuSO}_{4}$ were removed from the experiment, since the value was zero in assay three (Table S2). Sawdust was also excluded from the study because it is a substrate with large raw material variation, which can lead to changes in the results. Thus, glucose, malt extract, and wheat bran were selected to continue the optimization using a central composite design (CCD).

Results from the first CCD showed that the rate of decolorization was similar to P\&B 12 (Supplementary material, Table S3), not reaching the optimal conditions, even though some factors were highly significant (Table 1). Therefore, a new CCD was undertaken removing the variable glucose, which was not significant, and working on a narrower range of the significant variables malt extract and wheat bran. In this second CCD (Table 1), $90 \%$ of decolorization was achieved (assay two and six), and the significant variables were wheat bran quadratic and the interaction of malt extract with wheat bran (Supplementary material, Table S5). By applying multiple regression analysis to the experimental data, the second-order polynomial function was established (Table S5):

RB5 decolorization by Peniophora sp. CBMAI $1063=89.91$ -9.99 wheat bran $^{2}-14.99$ malt extract versus wheat bran

The statistical significance (Supplementary material, Table S6) was checked by an F test (ANOVA). As the F test, value (98.7) for the regression was highly significant (higher than the F tabulated (3.01)), and the percentage of variation explained by the model was suitable $\left(R^{2}=96 \%\right)$, the model could be considered to be predictive and was used to generate a contour plot and response surface (Fig. 1). The results derived from the response surface show that the study was close to the optimization point, working with a maximum of malt extract $(3 \mathrm{~g} / \mathrm{L})$ and the minimum of wheat bran (x axis) or at the other extreme with a maximum of bran wheat $(5 \mathrm{~g} / \mathrm{L})$ and malt extract at minimum (y axis).

To confirm the adequacy of the model equations, confirmatory experiments under the optimized condition were carried out. In the model, validation $94 \%$ of RB5 dye was decolorized after 7 days of incubation.

\section{Evaluation of RB5 dye degradation and mutagenicity}

Data from LC-MS confirm the reduction of $98 \%$ in the dye concentration after 7 days of fungal incubation, and in the model validation experiment, the absorption spectrum showed that no new peak was formed during the process (Fig. 2). Interestingly, after $24 \mathrm{~h}$ of the RB5 addition, the dye concentration was reduced from 200 to $41 \mathrm{mg} / \mathrm{L}$, meaning that 


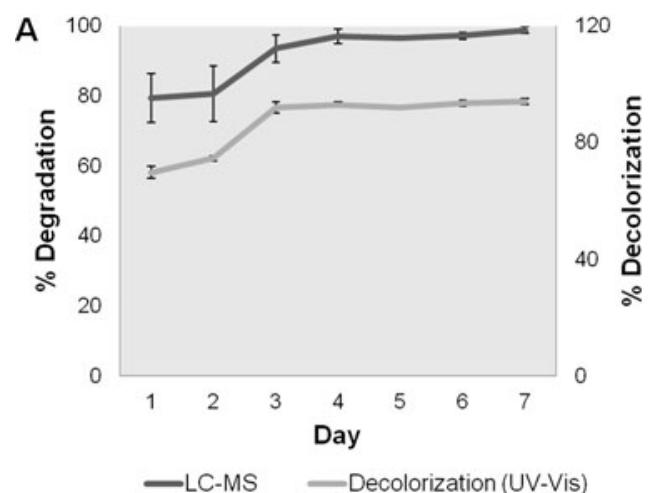

Fig. 2 a RB5 decolorization and degradation (LC-MS) percentages after Peniophora sp. CBMAI 1063 treatment for 7 days. b Absorbance spectrum in the wavelengths $300,400,500,600$, and $700 \mathrm{~nm}$ after

$79.5 \%$ of the dye was consumed or biotransformed in the initial process. After 7 days, $57 \%$ TOC reduction was observed $(798 \mathrm{mg} / \mathrm{L})$. The TOC of initial medium was around $1838 \mathrm{mg} / \mathrm{L}$ (dye TOC $\sim 265 \mathrm{mg} / \mathrm{L}$ ).

LC-MS monitoring identified mainly three metabolites after 7 days with molecular weight: 201, 281, and $439 \mathrm{~m} / \mathrm{z}$ (Table 2). These metabolites present similar $\mathrm{m} / \mathrm{z}$ and structure with p-Base and triaminohydroxynaphthalene disulfonic acid (TAHNDS) compounds that show variable molecular weights.

Results from AMES test (Maron and Ames 1983, supplementary material) revealed that no samples showed a mutagenic ratio (value higher than 2) and no statistical differences were obtained in ANOVA test against the negative control. These results indicate that the untreated RB5 dye and its metabolites do not exhibit mutagenic risk even after metabolism by the $\mathrm{S} 9$ fraction.

\section{Contribution of MnP and laccase in the RB5 dye decolorization}

$\mathrm{MnP}$ and Lac (Fig. 3) were produced during the decolorization but LiP was not detected. Lac- and MnP-specific PCR using complementary DNA (cDNA) template from RNA samples after the addition of RB5 dye expression increased, especially MnP (Fig. 3). The level of MnP expression was higher than

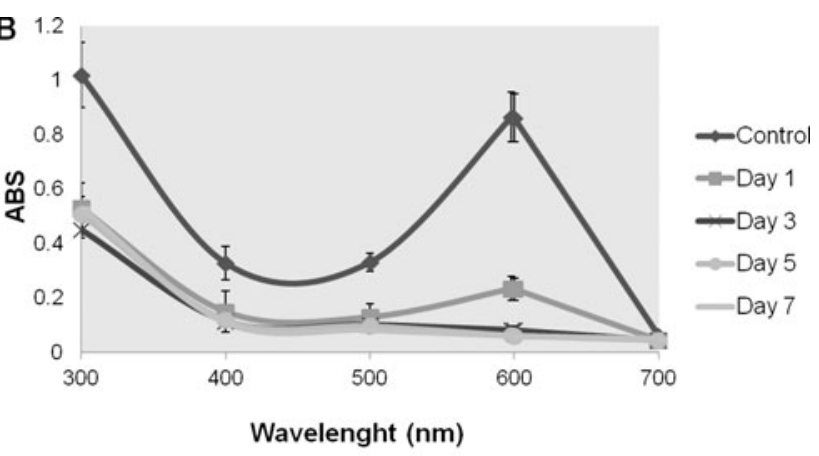

fungal treatment of RB5 for 7 days. Control line represents the spectra of dye-containing assay without the fungus

Lac, and MnP activity was detected from the second day. Lac was detected later, after the fifth day. A decrease of expression and extracellular MnP activity was observed after the fourth day, when the rate of decolorization was stabilized.

The analysis of the active fraction responsible for the dye decolorization "in vitro" (Supplementary material) showed that in conditions where Lac activity was evident, no decolorization was obtained in all of the days evaluated. On the other hand, under the conditions where $\mathrm{MnP}$ activity was evident, 73.4, 34.2 , and $1.6 \%$ of decolorization were observed on days 3 , 5 , and 7, respectively, only in the assay with $\mathrm{MnSO}_{4}$ and $\mathrm{H}_{2} \mathrm{O}_{2}$.

\section{Discussion}

Decolorization of RB5 by the marine-derived basidiomycete Peniophora sp. CBMAI 1063 could be considered highly promising since the process was efficient and occurred under saline condition. Considering that $92 \%$ of RB5 decolorization was achieved by the basidiomycete Phanerochaete chrysosporium in a previous study after 4 days using a lower concentration of the dye $(100 \mathrm{mg} / \mathrm{L}, 50 \%$ less than that used in the present study) and without saline condition (Enayatizamir et al. 2011), the results obtained in the present study demonstrate the potential of fungus from the marine environment for application in saline processes, such as textile
Fig. 3 Relative levels of laccase and $\mathrm{MnP}$ genes from Peniophora sp. CBMAI 1063 messenger RNA (mRNA) versus extracellular enzymes activities in the RB5 decolorization assay

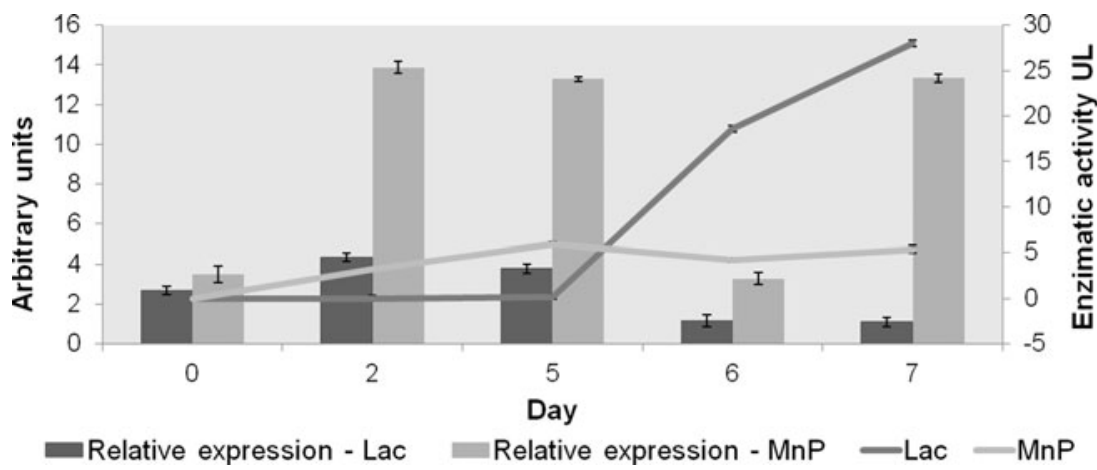


dyes degradation. The statistical methodology applied allowed a positive result in the optimization of RB5 decolorization by Peniophora sp. CBMAI 1063. The application of statistical experimental design techniques in decolorization process can result in improved removal, reduced process variability, closer confirmation of the output response to nominal and target requirements, and reduced development time and overall costs (Srinivasan and Murthy, 2009).

Data derived from AMES test showed that no mutagenic compounds were formed during RB5 dye decolorization by Peniophora sp. CBMAI 1063. This result reinforces the potential of this marine-derived fungus for biotechnological application (textile dye degradation), since it was able to highly degrade RB5 dye without generation of dangerous compounds. RB5 dye presented a moderate toxicity rate (using Microtox) even after degradation by the basidiomycete Trametes versicolor (Ramsay and Nguyen 2002).

During the process of RB5 degradation, no new peak was observed, indicating that decolorization process by the fungus involves the same biotransformation metabolites. Once the degraded percentage was very similar to the percentage of decolorization, results from degradation by LC-MS actually may represent the decolorization. The degradation occurred in two phases. In the first, the dye concentration decreased rapidly ( $24 \mathrm{~h}$ ), and the color of the solution remained purple. In the second, the dye concentration decreased slowly until it became colorless (144 h). According to Ip et al. (2010), complete decolorization involves two steps: (1) reduction of azo bond, resulting in a purple intermediate that still has a remaining azo bond (p-intermediate), and (2) further reduction of $\mathrm{p}$ intermediate azo bond. The first step is much faster than the second one, confirming the profile found in the present study. This two-step decolorization in RB5 is attributed to the reactivity difference between the hydroxyl $(-\mathrm{OH})$ and the amino $\left(-\mathrm{NH}_{2}\right)$ groups, which are the activating groups of aromatic electrophilic substitution at the ortho position related to the azo bonds (Enayatizamir et al. 2011). TAHNDS and p-Base compounds were identified during RB5 decolorization/degradation. TAHNDS are the main products obtained in a study related to RB5 anaerobic degradation using a bacterial culture and which have also been found in aerobic degradation processes (Rehorek and Plum 2006). These compounds are formed during reduction when cleavage of both azo bridges occurs (Rehorek and Plum 2006). To the best of our knowledge, this is the first report related to TAHNDS metabolites produced by filamentous fungus during RB5 dye degradation. In addition, the TOC analysis confirmed the degradation potential of RB5 by Peniophora sp. CBMAI 1063 since approximately $60 \%$ was reduced in only 7 days. Even though results from mutagenicity and LC-MS indicate that RB5 was degraded during the process (7 days), a longer process (assay) would be interesting for TOC stabilization. A higher TOC reduction could be obtained after more than 7 days of incubation.
Ligninolytic enzyme systems, particularly MnP, Lac, and LiP have been considered as the main factors responsible for the decolorization of dyes by white-rot basidiomycetes. As previously discussed, the first stage of RB5 degradation is a result of high oxidative action that leads to the generation of purple color compounds. Based on relative expression, probably this oxidation could be a result derived from the action of $\mathrm{MnP}$, which despite the lower extracellular activity compared with Lac, could directly oxidize this dye by transferring electrons from the protein surface (Heinfling et al. 1997). The analysis of the active fraction responsible for the dye decolorization confirmed this profile. In "in vitro" decolorization conditions, where Lac activity was evident, no decolorization was obtained in any of the days evaluated.

It is important to highlight that the expression of Lac was obtained from the first day, but its extracellular activity was detected only on day 5 , suggesting the existence of Lac fractions associated with cells not detected in supernatants (Solé et al. 2008). In this sense, the activity of Lac in decolorization of the RB5 dye cannot be ruled out. However, since the best rate of decolorization was observed between the second and third days (during the peak of expression and activity of $\mathrm{MnP}$ ), it is reasonable to believe that $\mathrm{MnP}$ is more involved mainly in the early stages of RB5 decolorization by the fungus Peniophora sp. CBMAI 1063. MnP has been reported as the major enzyme responsible for RB5 and other textile dyes decolorization by various microorganisms (Tang et al. 2011, Yang et al. 2003).

\section{Conclusion}

In the present study, integrated statistical design was successfully used to optimize the RB5 dye decolorization by Peniophora sp. CBMAI 1063, resulting in a very high rate of dye decolorization and degradation in saline conditions. The methodology provides an attractive solution for the screening and simultaneous optimization of the degradation process. Additionally, this study reports for the first time the metabolites generated during RB5 dye degradation by a basidiomycete fungus and the timing involvement of ligninolytic enzymes, including its gene expressions. The effectiveness of the dye biodegradation by Peniophora sp. CBMAI 1063 can also be proven by production of non-mutagenic metabolites, as observed in the AMES assay and by TOC reduction.

Additionally, results from phylogenetic analysis (supplementary material, Figure 4) revealed that ITS sequence of marine-derived Peniophora sp. CBMAI 1063 clustered with ITS sequences from fungal isolates from South America and Antarctic continents and formed a group clearly separated from the ITS fungal isolates from North America and Europe, a point to be explored in the sense of diversity and biotechnological potential of this genus. 
In conclusion, the polyphasic approach used in this study was successfully applied and highlights the potential of marine-derived fungus Peniophora sp. CBMAI 1063 for biotechnological application, stimulating future studies related to the treatment of textile effluent. This fungus could be considered as a target genetic resource for environmental pollutants degradation, especially in usages where land counterparts are deficient, such as in saline processes.

Acknowledgements R.C Bonugli-Santos was supported by a postdoctoral grant from Fundação de Amparo à Pesquisa do Estado de São Paulo-FAPESP (2009/18399-1), São Paulo, Brazil. The authors wish to thank FAPESP for its financial support (BIOTA-FAPESP grant 2010/ 50190-2 and FAPESP grant 2013/19486-0) and Roberto G. S. Berlinck for his help in LC-MS data analyses. L.D. Sette thanks CNPq for the Productivity Fellowship (304103/2013-6).

\section{References}

Bardi L, Marzona M (2010) Factors affecting the complete mineralization of azo dyes. Biodegradation of azo dyes. Handbook Environ Chem 9:195-210

Bonugli-Santos RC, Durrant LR, Sette LD (2010) Laccase activity and putative laccase genes in marine derived basidiomycetes. Fungal Biol 114:863-872

Bonugli-Santos RC, Durrant LR, Sette LD (2012) The production of ligninolytic enzymes by marine-derived basidiomycetes and their biotechnological potential in the biodegradation of recalcitrant pollutants and the treatment of textile effluents. Water Air Soil Poll 223: 2333-2345

Bonugli-Santos RC, Vasconcelos MRS, Passarini MRZ, Vieira GAL, Lopes VCP, Mainardi PH, dos Santos JA, Duarte LA, Otero IVR, Yoshida AMS, Feitosa VA, Pessoa Jr A,Sette LD (2015) Marinederived fungi: diversity of enzymes and biotechnological applications. Front Microbiol 6:269

Buswell JK, Cai YJ, Chang ST (1995) Effect of nutrient nitrogen on manganese peroxidase and lacase production by Lentinula (Lentinus) edodes. FEMS Microbiol Lett 128:81-88

Enayatizamir N, Tabandeh F, Rodríguez-Couto S, Yakhchali B, Alikhani HA, Mohammadi L (2011) Biodegradation pathway and detoxification of the diazo dye Reactive Black 5 by Phanerochaete chrysosporium. Bioresource Technol 102:10359-10362

Ghevariya CM, Bhatt JK, Dave BP (2011) Enhanced chrysene degradation by halotolerant Achromobacter xylosoxidans using response surface methodology. Bioresource Technol 102:9668-9674

Giardina P, Palmieri G, Fontanella B, Rivieccio V, Sannia G (2000) Manganese peroxidase isoenzymes produced by Pleurotus ostreatus grown on wood sawdust. Arch Biochem Biophys 376:171-179

Hadibarata T, Adnan LA, Yusoff ARM, Yuniart A, Rubiyatno, Zubir MMFA, Khudhair AB, Teh ZC, Abu Naser M (2013) Microbial decolorization of an azo dye Reactive Black 5 using white-rot fungus Pleurotus eryngii F032. Water Air Soil Poll 224:1595

Heinfling A, Bergbauer M, Szewzyk U (1997) Biodegradation of azo and phthalocyanine dyes by Trametes versicolor and Bjerkandera adusta. Appl Microbiol Biot 48:261-266

Ip AWM, Barford JP, McKay G (2010) Biodegradation of Reactive Black 5 and bioregeneration in upflow fixed bed bioreactors packed with different adsorbents. J Chem Technol Biot 85:658-667

Kaushik P, Malik A (2009) Fungal dye decolourization: recent advances and future potential. Environ Int 35:127-141
Kellner H, Luis P, Buscot F (2007) Diversity of laccase-like multicopperoxidase genes in Morchellaceae: identication of genes potentially involved in extracellular activities related to plant litter decay. FEMS Microbiol Ecol 61:153-163

Khan R, Bhawana P, Fulekar MH (2013) Microbial decolorization and degradation of synthetic dyes: a review. Rev Environ Sci Biot 12: $75-97$

Liu Q, Zhang X, Zhou Y, Zhao A, Chen S, Qian G, Xu ZP (2011) Optimization of fermentative biohydrogen production by response surface methodology using fresh leachate as nutrient supplement. Bioresource Technol 102(2011):86618668

Maron DM, Ames BN (1983) Revised methods for the Salmonella mutagenicity test. Mutat Res 113:173-215

Menezes CB, Bonugli-Santos RC, Miqueletto PB, Passarini MRZ, Silva CHD, Justo MR, Leal RR, Fantinatti-Garboggini F, Oliveira VM, Berlinck RG, Sette LD (2010) Microbial diversity associated with algae ascidians and sponges from the north coast of São Paulo state, Brazil. Microbiol Res 165: $466-482$

Morgenstern I, Klopman S, Hibbett DS (2008) Molecular evolution and diversity of lignin degrading heme peroxidases in the Agaricomycetes. J Mol Evol 66:243-257

Pearce AR, Rizzo DM, Watzin MC, Druschel GK (2013) Unraveling associations between cyanobacteria blooms and in-lake environmental conditions in Missisquoi Bay, Lake Champlain, USA, using a modified self-organizing map. Environ Sci Technol 47: $14267-14274$

Raghukumar C, D'Souza-Ticlo D, Verma AK (2008) Treatment of colored effluents with lignin-degrading enzymes: an emerging role of marine-derived fungi. Crit Rev Microbiol 34:189-206

Ramsay JA, Nguyen T (2002) Decoloration of textile dyes by Trametes versicolor and its effect on dye toxicity. Biotechnol Lett 24:1757-1761

Rehorek A, Plum A (2006) Online LC-MS-MS process monitoring for optimization of biological treatment of wastewater containing azo dye concentrates. Anal Bioanal Chem 384: $1123-1128$

Sette LD, Passarini MRZ, Delarmelina C, Salati F, Duarte MCT (2006) Molecular characterization and antimicrobial activity of endophytic fungi from coffee plants. World J Microb Biot 22: 1185-1195

Singh AK, Prakash D, Shahi SK (2013) Decolorization of the textile dye (Brown GR) by isolated Aspergillus strain from Meerut region. Int Res J Environ Sci 2:25-29

Solé M, Kellner H, Brock S, Buscot F, Schlosser D (2008) Extracellular laccase activity and transcript levels of putative laccase genes during removal of the xenoestrogen technical nonylphenol by the aquatic hyphomycete Clavariopsis aquatic. FEMS Microbiol Lett 288:47-54

Srinivasan SV, Murthy DVS (2009) Statistical optimization for decolorization of textile dyes using Trametes versicolor. J Hazard Mater 165:909-914

Tang W, Jia R, Zhang DM (2011) Decolorization and degradation of synthetic dyes by Schizophyllum sp. F17 in a novel system. Desalination 265:22-27

Tien M, Kirk TK (1984) Lignin-degrading enzyme from Phanerochaete chrysosporium: purification, characterization, and catalytic properties of unique $\mathrm{H} 2 \mathrm{O} 2$ requiring oxygenase. P Natl Acad Sci 81:2280-2284

Trincone A (2010) Potential biocatalysts originating from sea environments. J Mol Catal B-Enzym 66:241-256

Usha MS, Sasirekha B, Bela RB, Devi S, Kamalini C, Manasa GA (2006) Optimization of Reactive Black 5 dye and Reactive Red 120 dye degradation. J Chem Pharmaceut Res 3:450-457 
Xingzu W, Xiang C, Dezhi S, Hong Q (2008) Biodecolorization and partial mineralization of Reactive Black 5 by a strain of Rhodopseudomonas palustris. J Environ Sci 20:1218-1225

Yang Q, Yang M, Pritsch K, Yediler A, Hagn A, Schloter M, Kettrup A (2003) Decolorization of synthetic dyes and production of manganese-dependent peroxidase by new fungal isolates. Biotechnol Lett 25:709-713

Yingling B, Zhengfang Y (2013) Application of an integrated statistical design for optimization of culture condition for ammonium removal by nitrosomonas europaea. Plos One 8:1-11
Zeng T, Arnold WA (2014) Clustering chlorine reactivity of haloacetic acid precursors in Inland Lakes. Environ Sci Technol 48:139-148

Zeng X, Caia Y, Liaoa X, Zenga X, Li W, Zhangb D (2011) Decolorization of synthetic dyes by crude laccase from a newly isolated Trametes trogii strain cultivated on solid agro-industrial residue. J Hazard Mater 187:517-525 